\title{
TO EVALUATE THE EFFECT OF LOW DOSE FENTANYL-MIDAZOLAM COMBINATION ON SEVOFLURANE/PROPOFOL INDUCTION IN ADULT USING LARYNGEAL MASK AIRWAY: A COMPARATIVE STUDY
}

\author{
Ashish Pareek ${ }^{1}$ Sneha Bhataia², Sadhana Jain ${ }^{3}$
}

${ }^{1}$ Senior Resident, Department of Anaesthesia, PGIMER, Chandigarh.

2 Senior Demonstrator, Department of Pharmacology, R.N.T. Medical College, Udaipur.

3Professor, Department of Anaesthesia, S.P. Medical College, Bikaner.

\section{ABSTRACT}

\section{BACKGROUND AND AIM}

Airway management is the medical process of ensuring an open pathway for patient's lungs and ensuring the lungs are safe from aspiration. This study was conducted to investigate the effect of combination of low-dose Fentanyl-Midazolam premeditation on speed of insertion of laryngeal mask airway and to evaluate the laryngeal mask airway easy insertion conditions.

\section{MATERIAL AND METHODS}

The study was conducted in 80 patients presenting in Department of Anaesthesia. Pre-anaesthetic check-up was carried out on a day before surgery. Various techniques like route of giving anaesthesia, Vital Capacity Breath (VCB) technique and LMA insertion technique were used.

\section{RESULT}

Maximum number of patients was in age group 36-45. In group AI (sevoflurane group) and BI (propofol group) anxiety scale score was 4-6, while in Group AII (Inhalational Sevoflurane + I.V. Midazolam + I.V. Fentanyl and BII (I.V. Propofol with Lignocaine + I.V. Midazolam + I.V. Fentanyl) it was 2-3. In patient's loss of eyelash reflex for group BII is 30 seconds, AII group 31-40 seconds. In group $\mathrm{AI}$ and $\mathrm{BI}$, it was between 41-50 seconds. In most of the cases LMA insertion was seen in first attempt. In group BII, all patients had patent airway with LMA in the first attempt.

\section{CONCLUSION}

Administration of low-dose Fentanyl-Midazolam combination prior to Sevoflurane and Propofol induction decreases patient's anxiety levels and time of loss of eyelash reflex.

\section{KEYWORDS}

Fentanyl-Midazolam Combination, Anaesthetic Technique, Vital Capacity Breath (VCB) Technique, LMA Insertion Technique, Eyelash Reflex.

HOW TO CITE THIS ARTICLE: Pareek A, Bhataia S, Jain S. To evaluate the effect of low dose fentanyl-midazolam combination on sevoflurane/propofol induction in adult using laryngeal mask airway: a comparative study. J. Evolution Med. Dent. Sci. 2016;5(59): 4086-4091, DOI: $10.14260 /$ jemds/2016/935

\section{INTRODUCTION}

There are a variety of artificial airways, which can be used to keep a pathway between the lungs and mouth/nose. The most commonly used in long-term or critical care situation is the endotracheal intubation, placement of flexible plastic or rubber tube into trachea.

Alternative technique for airway management and delivery of oxygen, volatile anaesthetics or other breathing gases include the laryngeal mask airways, cuffed oropharyngeal airway, CPAP mask, nasal BiPAP mask, simple face mask and nasal cannula. Supraglottic airway devices have become a standard fixture in airway management, filling a niche between the face mask and tracheal tube and provide a hands free means of achieving a gas tight airway.

Financial or Other, Competing Interest: None.

Submission 15-06-2016, Peer Review 07-07-2016,

Acceptance 15-07-2016, Published 23-07-2016.

Corresponding Author:

Dr. Ashish Pareek,

113/10, "Atishay"

Opposite Savitri School,

Civil Lines,

Ajmer-305001,

E-mail: drashish0141@gmail.com

DOI: 10.14260/jemds/2016/935
AIJ Brain. ${ }^{1}$ (1983) invented the LMA and gave the new concept in airway management, which provided an effective mean of securing a clean airway in fasting patients for elective anaesthesia and emergency airway management. As time went on, additional devices were added to the LMA family to satisfy specific need and a number of other devices were developed, e.g. Soft seal laryngeal mask, Ambu laryngeal mask, Laryngeal tube airway, Streamlined pharynx airway liner.

Smooth insertion of LMA requires relaxation of jaw and attenuation of airway reflexes sufficient to abolish the gag reflex. Midazolam is a benzodiazepine, commonly used to provide sedation or induction of anaesthesia. It produces tranquility, smoothen induction, loss of recall of perioperative events. Although respiratory depression is less common after Midazolam induction, even small I.V. dose of Midazolam has resulted in respiratory arrest.

\section{THE AIM OF THIS STUDY WAS}

1. To investigate the effect of combination of low-dose Fentanyl-Midazolam premeditation on speed of insertion of laryngeal mask airway.

2. To evaluate the laryngeal mask airway easy insertion conditions.

3. To evaluate haemodynamic stability. 


\section{MATERIALS \\ Apparatus}

Anaesthesia work station with multipara monitor or Boyle's machine with full $\mathrm{O}_{2}$ and $\mathrm{N}_{2} \mathrm{O}$ cylinder, Sevoflurane vaporizer, Classic laryngeal mask airway No. 3 and 4, Endotracheal tubes of appropriate size, Laryngoscope, Pulse oximeter, Sphygmomanometer, Weighing machine, Stethoscope, I.V. Cannula Transfusion set, I.V. fluids; Disposable syringes 2, 5 and $10 \mathrm{cc}$; Suction apparatus.

\section{Drugs}

- Sevoflurane.

- Inj. Propofol (1\% (10 mg/mL); 10, 20, $50 \mathrm{~mL}$ vial).

- Inj. Midazolam (1 mg/mL; $5 \mathrm{~mL}$ vial).

- Inj. Fentanyl (50 $\mu \mathrm{g} / \mathrm{mL} ; 2 \mathrm{~mL}$ amp).

\section{Emergency Drugs}

Inj. Atropine sulphate, Inj. Dexamethasone, Inj. Hydrocortisone, Inj. Pheniramine maleate, Inj. Mephentermine, Inj. Deriphyllin, Inj. Diazepam, Inj. Adrenaline, Inj. Dopamine, Inj. Frusemide, Inj. Sodium bicarbonate, Inj. Calcium gluconate.

\section{METHODS}

\section{Selection of Patients}

After Institutional Research Board approval for plan of thesis and written informed consent from patients, the study was conducted in 80 patients presenting in Department of Anaesthesia. The patients were of either gender belonging to ASA grade I and II between the age group of 18 to 65 years scheduled for elective surgery under general anaesthesia.

\section{Exclusion Criteria}

1. History of difficult intubation or likely to be difficult to intubate.

2. Gastro-oesophageal reflux disease.

3. Allergy or sensitivity to volatile anaesthetics or to Propofol.

4. Body mass index more than $32 \mathrm{~kg} / \mathrm{m}^{2}$.

5. Heavy smoker $>20$ cigarettes per day.

6. Patients taking any sedative drugs that influence the induction anaesthetic.

7. Impaired ability to communicate (e.g. confusion, poor hearing or language barrier.

Pre-anaesthetic check-up was carried out on a day before surgery.

Anaesthetic Technique: The study was conducted in 80 patients. All patients were divided into two groups A and B, which further subdivided into four subgroups AI, AII and BI, BII.

\begin{tabular}{|c|c|c|}
\hline Group & Drug \& Doses & $\begin{array}{c}\text { No. of } \\
\text { Patients }\end{array}$ \\
\hline A & \multicolumn{2}{|c|}{ Sevoflurane Group } \\
\hline AI & Inhalational Sevoflurane $(8 \%)$ & 20 \\
\hline AII & $\begin{array}{c}\text { Inhalational Sevoflurane }(8 \%)+ \\
\text { I.V. Midazolam }(9 \mu \mathrm{g} / \mathrm{kg})+\mathrm{I} . \mathrm{V} . \\
\text { Fentanyl }(0.6 \mu \mathrm{g} / \mathrm{kg})\end{array}$ & 20 \\
\hline B & \multicolumn{2}{|c|}{ Propofol Group } \\
\hline
\end{tabular}

\begin{tabular}{|c|c|c|}
\hline BI & $\begin{array}{c}\text { Intravenous Propofol }(3 \mathrm{mg} / \mathrm{kg}) \\
\text { with Lignocaine }(0.3 \mathrm{mg} / \mathrm{kg})\end{array}$ & 20 \\
\hline BII & $\begin{array}{c}\text { I.V. Propofol }(3 \mathrm{mg} / \mathrm{kg}) \text { with } \\
\text { Lignocaine +I.V. Midazolam } \\
(9 \mu \mathrm{gg} / \mathrm{kg})+\mathrm{I} . V . \text { Fentanyl }(0.6 \mu \mathrm{g} / \mathrm{kg})\end{array}$ & 20 \\
\hline
\end{tabular}

Prior to entering the operating room, anxiety level on Verbal Numerical Scale (VNS) from 0 to 10 ( 0 being the lowest and 10 being the highest anxiety level) was recorded. On arrival of the patient in operating room, an I.V. cannula $18 \mathrm{G}$ was secured. Intravenous drip to ringer lactate solution was started. Standard monitoring with non-invasive blood pressure measurement, pulse, heart rate and $\mathrm{SPO}_{2}$ were recorded pre-operatively. At this stage, the VNS anxiety level was reassessed.

Inj. Fentanyl $0.6 \mu \mathrm{g} / \mathrm{kg}$ and Inj. Midazolam $9 \mu \mathrm{g} / \mathrm{kg}$ were given as a pre-anaesthetic medication in group AII and BII. Five minutes after the injection, the VNS anxiety level was reevaluated for the third time, just before induction.

Anaesthesia was induced with a single Vital Capacity Breath (VCB) of inhalational Sevoflurane 8\% (Group A) in a 2:1 ratio of nitrous oxide to oxygen at a fresh gas flow rate of 6 $\mathrm{L} / \mathrm{min}$ and intravenous Propofol $3 \mathrm{mg} / \mathrm{kg}$ (Group B). A prior injection of Lignocaine $0.3 \mathrm{mg} / \mathrm{kg}$ was given intravenously to the Propofol group for pain reduction.

\section{Vital Capacity Breath (VCB) Technique}

For patients in the Sevoflurane group, a circle $\mathrm{CO}_{2}$ absorber circuit with a $3 \mathrm{~L}$ reservoir bag was used. The circuit was primed with Sevoflurane $8 \%$ in a 2:1 ratio of nitrous oxide to oxygen at a fresh gas flow of $6 \mathrm{~L} / \mathrm{min}$ for $1 \mathrm{~min}$. While breathing $100 \%$ oxygen from a separate breathing system, the patients were asked to take a deep breath and then exhale to residual volume. The mask with the primed circuit was then placed firmly over the patient's face. The patients were instructed to inhale a VCB and hold it as long as possible. If necessary, a second breath was taken. The start of induction was taken as the point at which the patients completed their VCB. While holding their breath, the patients were asked to open their eyes every $10 \mathrm{~s}$. Failure to do so was taken as loss of consciousness. This was confirmed by testing for the loss of eyelash reflex. Ninety seconds after completing the VCB to achieve equilibrium between the alveolar concentration of Sevoflurane and the brain, the ease of mouth opening was assessed (Possible or impossible). If mouth opening was impossible, another attempt was made every $30 \mathrm{~s}$ up to a maximum of 4 tries. Between attempts, anaesthesia was maintained with Sevoflurane at a dial concentration of $8 \%$ in a $2: 1$ ratio of nitrous oxide to oxygen at $6 \mathrm{~L} / \mathrm{min}$.

\section{LMA Insertion Technique}

The first step was to examine the airway tube and mask of laryngeal mask airway. The next step was to withdraw air from the cuff, so that the walls were flattened against each other. Lubrication was applied to the posterior cuff surface just before insertion, taking care to avoid lubricant on the anterior surface.

The standard insertion technique was used as a midline or slightly diagonal approach. The head was extended and the neck flexed (Sniffing position). That position was best maintained during insertion by using the non-inserting hand to stabilize the occiput. Push the jaw downward and hold the 
LMA like a pen with index finger at the junction of tube and cuff. As the LMA was advanced, the mask portion was pressed against the hard palate by using the index finger. After checking bilateral equal inflation and leak of cuff, the tube and mouth prop were fixed centrally. Number of attempts and time required for LMA insertion were noted. All the patients in the study were attained by the same professional.

Anaesthesia was maintained with Sevoflurane and isoflurane, $\mathrm{N}_{2} \mathrm{O}$ in $\mathrm{O}_{2}$ and vecuronium bromide using a standard technique. On completion of the surgery neuromuscular block was antagonized with neostigmine and glycopyrrolate. LMA was removed after deflating the cuff when the patient regained consciousness.

\section{RESULT AND OBSERVATIONS}

This study was done to evaluate the effect of low-dose Fentanyl-Midazolam combination on Sevoflurane/Propofol induction in adult using laryngeal mask airway; 80 patients between 18 to 65 years were divided into two groups $A(n=40)$ and $B(n=40)$, which further divided into four sub-groups AI $(n=20)$, AII $(n=20)$ and BI $(n=20), B I I(n=20)$. Group AI patients received Inhalational Sevoflurane $(8 \%)$, group AII patients received Inhalational Sevoflurane (8\%) + I.V. Midazolam (9 $\mu \mathrm{g} / \mathrm{kg})+\mathrm{I} . \mathrm{V}$. Fentanyl $(0.6 \mu \mathrm{g} / \mathrm{kg})$, while group BI patients received Intravenous Propofol ( $3 \mathrm{mg} / \mathrm{kg}$ ) with Lignocaine $(0.3$ $\mathrm{mg} / \mathrm{kg}$ ) and group BII Intravenous Propofol (3 mg/kg) with Lignocaine $(0.3 \mathrm{mg} / \mathrm{kg})+$ I.V. Midazolam $(9 \mu \mathrm{g} / \mathrm{kg})+$ I.V. Fentanyl $(0.6 \mu \mathrm{g} / \mathrm{kg})$.

The age of the patients under the study ranged between 18 to 65 years. Maximum numbers of patients were in age group 36-45 in all groups. The mean age of the patients was $37.35 \pm 12.44,39.85 \pm 11.40,42.10 \pm 11.17,39.30 \pm 9.76$ for group $\mathrm{AI}, \mathrm{AII}, \mathrm{BI}$ and BII respectively.

All the patients were monitored for anxiety level, time to loss of eyelash reflex, number of attempts for LMA insertion.

Anxiety levels were similar between the all groups before and immediately after the patients entered the operating room. Five minutes after the administration of the study premedication, patient in group AII and group BII had less anxiety levels $(2.35+0.59$ and $2.20+0.83$ respectively) compared with patients in group AI and BI $(5.25+0.85$ and $5.15+0.75$ respectively) $(\mathrm{p}<0.001)$.

In our study, the time of loss of eyelash reflex were significantly shorter in group AII and BII $(32.25+1.99$ and $27.20+1.94$ respectively) as compared with group AI and BI $(48.20+2.95$ and $42.75+1.65$ respectively) ( $p<0.001)$. Minimum time was observed in Propofol with premedication (group BII).

The attempts of LMA insertion were significantly less in number in group AII and BII $(1.05+0.22$ and $1.00+0.00$ respectively) as compared with group $\mathrm{AI}$ and $\mathrm{BI}(1.25+0.44$ and $1.20+0.41$ respectively) ( $\mathrm{p}<0.001)$.

Pulse rate, systolic blood pressure and diastolic blood pressure revealed lower values in the group AII and BII, which were statistically significant when compared to group AI and BI respectively $(\mathrm{p}<0.001)$.

\section{DISCUSSION}

Airway management is a primary consideration in anaesthesia, cardiopulmonary resuscitation, emergency medicine, intensive care medicine and first aid. The most widely used method for airway management is endotracheal intubation. Although, it offers the greatest degree of protection against regurgitation and pulmonary aspiration, tracheal intubation is not the only means to maintain a patent airway. Alternative techniques include the laryngeal mask airway. Advantages over intubation includes less workload, less marked increase in blood pressure and heart rate, less anaesthesia is needed, smoother emergence and shorter recovery times.

Induction regime for LMA insertion should provide a depth of anaesthesia with a relaxed jaw and suppressed airway reflexes for the device to be tolerated within the hypopharynx without undue coughing, gagging and patient movement. Such conditions are provided by a generous dose of an induction agent. The pre-anaesthetic medication are the drugs used prior to the administration of an anaesthetic agent to make anaesthesia safe and more agreeable to the patients, reduce anxiety and apprehension, synergistic/additive effect for smooth and rapid induction, counteract adverse effects of anaesthetic drugs and relief from pain.

The present study was designed to evaluate the effect of low-dose Fentanyl-Midazolam combination on Sevoflurane/Propofol induction in adult using laryngeal mask airway.

Data from 80 patients between 18 to 65 years were analysed. The patients in all groups were comparable in terms of age, sex and ASA status.

Both male and female patients were included in this study. A female predominance was seen in our study.

Patients were randomly selected, so no statistical difference was seen among the four groups according to the age and sex of the patient.

This study suggests that premedication with low-dose Fentanyl-Midazolam combination may be an attractive solution for reducing anxiety. A significant number of patients who received premedication did not remember breathing through a mask.

The hypnotic properties of Midazolam studied by Nishiyama T, Matsukawa T et $\mathrm{al}^{2}$ (2002) may well explain these findings. They concluded that addition of I.V. Midazolam provides more stable haemodynamic cardiac autonomic nervous system activity, patient satisfaction and decreased anxiety with Sevoflurane.

In this study, the time to loss of eyelash reflex in group AI (Without premedication) approximately $50 \mathrm{sec}$ and in AII was 35 sec. Similar result was observed by Ti, Lian Kah et al ${ }^{3}$ (1999). They compared the quality and ease of laryngeal mask airway insertion after either rapid inhaled Sevoflurane or I.V. Propofol induction of anaesthesia. The LMA was inserted more rapidly in patients in the Propofol group (74+/-29 Vs 127+/35 s; $\mathrm{P}<.01$ ) and required fewer attempts than Sevoflurane group.

Sahar M Siddik-Sayyid et al ${ }^{4}$ (2005) compared SevofluranePropofol (SP) versus Sevoflurane (S) or Propofol (P) for laryngeal mask airway insertion in adults. Patients in groups $S$ $(45 \pm 12)$ and SP $(47 \pm 8)$ had a longer time to loss of eyelash reflex as compared with patients in group $\mathrm{P}(39 \pm 9)(\mathrm{P} \pm 0.03)$

These differences in time of loss of eyelash reflex can be explained by the different ways inhalation induction of anaesthesia with Sevoflurane in adults can be performed. Basically, anaesthesiologists may ask their patients to breathe normally or they may choose to rely on the single breath inhalation technique. 
Sandra Lesage, Pierre droplet et $\mathrm{al}^{5}$ (2009) investigated that administration of a low-dose Fentanyl-Midazolam combination prior to Sevoflurane induction decreases time of LER (Loss of Eyelash Reflex) and allows for more rapid and less eventful LMA insertion. The results of our study in group AII were similar as above mentioned study. The attempts of LMA insertion were significantly less in number in group AII and BII $(1.05+0.22$ and $1.00+0.00$ respectively) as compared with group $\mathrm{AI}$ and $\mathrm{BI}(1.25+0.44$ and $1.20+0.41$ respectively) $(\mathrm{p}<0.001)$.

In our patients, induction of anaesthesia with Sevoflurane alone was associated with a prolonged time to jaw relaxation and a delay in insertion of the LMA as compared with induction of anaesthesia with Propofol. Also, more attempts at insertion were required in Sevoflurane group. Several previous reports support our findings and show that anaesthetic induction with Sevoflurane results in a longer time to jaw relaxation and even jaw tightness that may result in delay or failure to insert the LMA.

Our results are comparable to those achieved by Ti et al ${ }^{3}$ (1999), who compared LMA insertion after induction of anaesthesia with either single VCB of Sevoflurane $8 \%$ or IV Propofol $3 \mathrm{mg} / \mathrm{kg}$. They concluded that Sevoflurane compares favourably with Propofol, although prolonged jaw tightness may delay LMA insertion.

S.B. Ganatra et $a^{6}$ (2002) compared the condition for insertion of LMA using Sevoflurane or Propofol plus Fentanyl. They concluded that there was a faster induction with Propofol-Fentanyl.

Sahar M Siddik-Sayyid etal ${ }^{4}$ (2005) compared SevofluranePropofol versus Sevoflurane or Propofol for laryngeal mask airway insertion in adults. The report showed that induction of anaesthesia using the combination of Sevoflurane-Propofol resulted in most frequent successful LMA insertion at first attempt as compared with induction of anaesthesia with either Sevoflurane or Propofol alone.

The intravenous low-dose Fentanyl-Midazolam combination seems to have dampened the haemodynamic response to LMA insertion. Pulse rate, systolic blood pressure and diastolic blood pressure revealed lower values in the group AII and BII, which were statistically significant when compared to group AI and BI respectively $(\mathrm{p}<0.001)$.

Laryngeal mask airway insertion provides avoidance of laryngoscopy and endotracheal intubation and cause better haemodynamic profile as compared to intubation and it can also be correlated with study done by Cork RC, Depa RM et al ${ }^{7}$ (1994), Zimmert M, Zwirner P et al ${ }^{8}$ (1999) and M Shafique Tahir, Nadeem Ahmad Khan et $\mathrm{al}^{9}$ (2008). They all have found that laryngeal mask airway is an acceptable alternative technique offering advantages in terms of haemodynamic stability compared to tracheal intubation.

Hall JE et al ${ }^{10}$ (1997) studied single-breath inhalation induction of Sevoflurane anaesthesia with and without nitrous oxide and comparison with an intravenous bolus of Propofol. They concluded that there was more excitation in the gaseous induction groups. Cardiovascular stability was good and comparable in all groups.

Muzi M, Colinco MD et al ${ }^{11}$ (1997) studied the effects of premedication on inhaled induction of anaesthesia with Sevoflurane. The effects of premedication with Midazolam (M), Fentanyl (F) or both (B) on induction of anaesthesia via a mask with Sevoflurane (S) were assessed. They concluded that giving patients small doses of sedatives intravenously before they inhale an anaesthetic can improve the speed and quality of the process of falling asleep.

The choice of drugs and doses in our study was influenced by Muzi M, Colinco MD et al11 (1997) who showed that this particular combination accelerated an improved condition for endotracheal intubation. Muzi's dosages were selected because of a previous study by Ben-Shlomo et al ${ }^{12}$ (1990) showing that Fentanyl and Midazolam act synergistically and that 25\% of the ED50 of Fentanyl was required in combination with $23 \%$ of the ED50 for Midazolam to achieve the ED50 of the combination.

Still contrary to Muzi et al, we opted for classic LMA use instead of tracheal intubation. Therefore, may be even lower dosages could have been appropriate, since LMA insertion is far less stimulating than direct laryngoscopy and endotracheal intubation.

Katoh T. Takasumi et al ${ }^{13}$ (1999) studied that Fentanyl 4 micrograms kg-1 suppressed the changes in HR and MAP more effectively than Fentanyl 1 or 2 micrograms kg- 1 at Sevoflurane concentrations close to MAC-T.

Sivalingam $P$ et al ${ }^{14}$ (1999) have shown that the use of premedication during Sevoflurane induction could lower systolic blood pressure and heart rate, but generally they remain within normal limit

Nishiyama T, Matsukawa $\mathrm{T}$ et $\mathrm{al}^{2}$ (2002) concluded that addition of I.V. Midazolam provides more stable haemodynamic cardiac autonomic nervous systemic activity and patient satisfaction with Sevoflurane.

S.B. Ganatra et $\mathrm{al}^{6}$ (2002) compared the condition for insertion of LMA using Sevoflurane or Propofol plus Fentanyl. They concluded that faster induction seen with PropofolFentanyl. Haemodynamic stability was better with Sevoflurane Fentanyl.

Dutt A et al ${ }^{8}$ (2012) studied Fentanyl in doses $1 \mu \mathrm{g} / \mathrm{kg}$ and $2 \mu \mathrm{g} / \mathrm{kg}$ with Propofol in classical LMA insertion. They concluded that both the doses provided optimal conditions for LMA insertion when Propofol was used in dose of $2.5 \mathrm{mg} / \mathrm{kg}$. Low-dose Fentanyl $(1 \mu \mathrm{g} / \mathrm{kg})$ provided a more stable haemodynamic profile with fewer episodes of hypotension and bradycardia.

However, caution is warranted since adding opioids in premedication to particularly sufentanil and remifentanil has been linked to asystolic episodes.

Cardinal V, Martin R et al15 (2004) observed that the addition of sufentanil, even at very low doses during anaesthesia induction with Sevoflurane using a single breath technique may be dangerous, because of possible bradycardia and even asystole. 


\begin{tabular}{|c|c|c|c|c|c|c|c|c|}
\hline \multirow{2}{*}{ Age Group (Years) } & \multicolumn{2}{|c|}{ Group AI } & \multicolumn{2}{|c|}{ Group AII } & \multicolumn{2}{|c|}{ Group BI } & \multicolumn{2}{|c|}{ Group BII } \\
\hline & No. & $\%$ & No. & $\%$ & No. & $\%$ & No. & $\%$ \\
\hline $18-25$ & 5 & 25.0 & 2 & 10.0 & 3 & 15.0 & 3 & 15.0 \\
\hline $26-35$ & 2 & 10.0 & 4 & 20.0 & 2 & 10.0 & 3 & 15.0 \\
\hline $36-45$ & 8 & 40.0 & 11 & 55.0 & 6 & 30.0 & 9 & 45.0 \\
\hline $46-55$ & 3 & 15.0 & 1 & 5.0 & 8 & 40.0 & 4 & 20.0 \\
\hline $56-65$ & 2 & 10.0 & 2 & 10.0 & 1 & 5.0 & 1 & 5.0 \\
\hline Total & 20 & 100 & 20 & 100 & 20 & 100 & 20 & 100 \\
\hline Mean & \multicolumn{2}{|c|}{37.35} & \multicolumn{2}{|c|}{39.85} & \multicolumn{2}{|c|}{42.10} & \multicolumn{2}{|c|}{39.30} \\
\hline SD & \multicolumn{2}{|c|}{12.44} & \multicolumn{2}{|c|}{11.40} & \multicolumn{2}{|c|}{11.17} & \multicolumn{2}{|c|}{9.76} \\
\hline
\end{tabular}

\begin{tabular}{|c|c|c|c|c|c|c|c|c|}
\hline \multirow{2}{*}{$\begin{array}{c}\text { Time of Loss of } \\
\text { Eyelash Reflex (Sec.) }\end{array}$} & \multicolumn{2}{|c|}{ Group AI } & \multicolumn{2}{|c|}{ Group AII } & \multicolumn{2}{|c|}{ Group BI } & \multicolumn{2}{|c|}{ Group BII } \\
\hline & No. & $\%$ & No. & $\%$ & No. & $\%$ & No. & $\%$ \\
\hline$<30$ & 0 & - & 6 & 30.0 & 0 & - & 20 & 100 \\
\hline $31-40$ & 0 & - & 14 & 70.0 & 2 & 10.0 & 0 & - \\
\hline $41-50$ & 17 & 85.0 & 0 & - & 18 & 90.0 & 0 & - \\
\hline$>50$ & 3 & 15.0 & 0 & - & 0 & - & 0 & - \\
\hline Total & 20 & 100 & 20 & 100 & 20 & 100 & 20 & 100 \\
\hline Mean & \multicolumn{2}{|c|}{48.20} & \multicolumn{2}{|c|}{32.25} & \multicolumn{2}{|c|}{42.75} & \multicolumn{2}{|c|}{27.20} \\
\hline SD & \multicolumn{2}{|c|}{2.95} & \multicolumn{2}{|c|}{1.99} & \multicolumn{2}{|c|}{1.65} & \multicolumn{2}{|c|}{1.94} \\
\hline $\mathbf{P}$ & \multicolumn{8}{|c|}{$<0.001$} \\
\hline
\end{tabular}

\begin{tabular}{|c|c|c|c|c|c|c|c|c|}
\hline \multirow{2}{*}{ Attempts } & \multicolumn{2}{|c|}{ Group AI } & \multicolumn{2}{|c|}{ Group AII } & \multicolumn{2}{|c|}{ Group BI } & \multicolumn{2}{|c|}{ Group BII } \\
\hline & No. & $\%$ & No. & $\%$ & No. & $\%$ & No. & $\%$ \\
\hline 1 & 15 & 75.0 & 19 & 95.0 & 16 & 80.0 & 20 & 100 \\
\hline 2 & 5 & 25.0 & 1 & 5.0 & 4 & 20.0 & 0 & - \\
\hline Total & 20 & 100 & 20 & 100 & 20 & 100 & 20 & 100 \\
\hline Mean & \multicolumn{2}{|c|}{1.25} & \multicolumn{2}{|c|}{1.05} & \multicolumn{2}{|c|}{1.20} & \multicolumn{2}{|c|}{1.00} \\
\hline SD & \multicolumn{2}{|c|}{0.44} & \multicolumn{2}{|c|}{0.22} & \multicolumn{2}{|c|}{0.41} & \multicolumn{2}{|c|}{0.00} \\
\hline $\mathbf{P}$ & \multicolumn{8}{|c|}{$<0.001$} \\
\hline
\end{tabular}

\begin{tabular}{|c|c|c|c|c|c|c|c|c|c|}
\hline & \multicolumn{2}{|c|}{ Group AI } & \multicolumn{2}{c|}{ Group AII } & \multicolumn{2}{c|}{ Group BI } & \multicolumn{2}{c|}{ Group BII } & \multirow{2}{*}{ P } \\
\cline { 2 - 10 } & Mean & SD & Mean & SD & Mean & SD & Mean & SD & \multirow{2}{*}{0.006} \\
\hline $\begin{array}{c}\text { Pre-Anaesthetic } \\
\text { Checkup }\end{array}$ & 78.20 & 4.58 & 81.10 & 1.89 & 78.10 & 5.17 & 81.50 & 2.96 & 2.06 \\
\hline Before Induction & 79.20 & 3.64 & 83.60 & 2.95 & 80.20 & 3.94 & 83.95 & 3.08 & $<0.001$ \\
\hline After Induction & 78.70 & 5.78 & 87.90 & 3.46 & 81.00 & 5.71 & 87.40 & 3.68 & $<0.001$ \\
\hline Just After LMA & 81.70 & 5.44 & 88.00 & 2.51 & 84.40 & 5.72 & 87.70 & 2.92 & 0.047 \\
\hline After 5 min. & 78.50 & 5.06 & 81.60 & 1.79 & 79.00 & 6.57 & 81.60 & 2.72 & $<0.001$ \\
\hline After 10 mins. & 84.10 & 4.28 & 81.80 & 3.11 & 86.80 & 4.65 & 81.30 & 3.13 & $<0.001$ \\
\hline After 15 mins. & 85.90 & 4.02 & 78.10 & 2.79 & 87.30 & 5.59 & 78.40 & 3.47 & $<0.001$ \\
\hline After 20 mins. & 87.90 & 5.17 & 77.80 & 3.17 & 90.10 & 3.97 & 78.80 & 2.71 & $<0.001$ \\
\hline After 30 mins. & 88.80 & 5.08 & 76.80 & 3.40 & 89.80 & 6.01 & 76.30 & 3.51 & $<0.001$ \\
\hline After 40 mins. & 91.80 & 4.25 & 75.50 & 3.66 & 93.10 & 4.23 & 77.00 & 3.58 & $<0.001$ \\
\hline After 50 mins. & 91.30 & 5.70 & 77.90 & 3.14 & 92.70 & 5.78 & 77.68 & 2.24 & $<0.001$ \\
\hline
\end{tabular}

\begin{tabular}{|c|c|c|c|c|c|c|c|c|c|}
\hline & \multicolumn{2}{|c|}{ Group AI } & \multicolumn{2}{c|}{ Group AII } & \multicolumn{2}{c|}{ Group BI } & \multicolumn{2}{c|}{ Group BII } & \multirow{2}{*}{ P } \\
\cline { 2 - 9 } & Mean & SD & Mean & SD & Mean & SD & Mean & SD & \\
\hline Pre-Anaesthetic Checkup & 123.30 & 4.01 & 120.25 & 2.43 & 123.50 & 4.35 & 120.90 & 3.75 & 0.011 \\
\hline Before Induction & 126.20 & 3.61 & 119.40 & 2.52 & 125.80 & 3.11 & 119.60 & 4.19 & $<0.001$ \\
\hline After Induction & 129.00 & 7.93 & 117.80 & 2.67 & 123.20 & 7.85 & 116.60 & 4.90 & $<0.001$ \\
\hline Just After LMA & 126.10 & 4.56 & 118.70 & 3.33 & 124.50 & 5.35 & 118.50 & 6.12 & $<0.001$ \\
\hline After 5 mins. & 133.80 & 6.12 & 116.30 & 3.91 & 130.60 & 7.49 & 116.50 & 5.35 & $<0.001$ \\
\hline After 10 mins. & 132.60 & 6.02 & 117.40 & 2.98 & 133.40 & 6.36 & 117.60 & 3.22 & $<0.001$ \\
\hline After 15 mins. & 134.40 & 4.03 & 117.70 & 2.77 & 134.00 & 4.15 & 116.80 & 3.33 & $<0.001$ \\
\hline After 20 mins. & 133.20 & 5.67 & 114.20 & 3.11 & 134.30 & 4.69 & 14.40 & 4.03 & $<0.001$ \\
\hline After 30 mins. & 134.90 & 5.00 & 119.40 & 3.90 & 135.20 & 4.27 & 118.60 & 3.32 & $<0.001$ \\
\hline After 40 mins. & 137.80 & 3.66 & 117.70 & 3.63 & 136.60 & 3.73 & 116.80 & 3.91 & $<0.001$ \\
\hline After 50 mins. & 131.50 & 4.94 & 119.00 & 3.64 & 132.30 & 4.07 & 118.42 & 5.48 & $<0.001$ \\
\hline After 60 mins. & 135.40 & 5.70 & 119.50 & 3.03 & 135.80 & 4.89 & 120.42 & 4.40 & $<0.001$ \\
\hline
\end{tabular}




\begin{tabular}{|c|c|c|c|c|c|c|c|c|c|}
\hline & \multicolumn{2}{|c|}{ Group AI } & \multicolumn{2}{c|}{ Group AII } & \multicolumn{2}{c|}{ Group BI } & \multicolumn{2}{c|}{ Group BII } & \multirow{2}{*}{ P } \\
\cline { 2 - 9 } & Mean & SD & Mean & SD & Mean & SD & Mean & SD & \multirow{2}{*}{0.124} \\
\hline $\begin{array}{c}\text { Pre-Anaesthetic } \\
\text { Checkup }\end{array}$ & 80.90 & 4.08 & 78.40 & 3.53 & 79.90 & 2.79 & 79.50 & 2.50 & 0.124 \\
\hline Before Induction & 78.90 & 5.60 & 77.90 & 4.08 & 78.70 & 5.70 & 78.70 & 2.70 & 0.910 \\
\hline After Induction & 77.80 & 5.94 & 76.30 & 4.37 & 76.40 & 6.48 & 78.10 & 4.66 & 0.624 \\
\hline Just After LMA & 79.40 & 5.28 & 77.00 & 3.15 & 77.90 & 5.89 & 78.70 & 2.72 & 0.353 \\
\hline After 5 mins. & 80.70 & 6.30 & 74.60 & 3.90 & 78.70 & 5.04 & 76.60 & 3.25 & $<0.001$ \\
\hline After 10 mins. & 85.50 & 4.94 & 74.80 & 5.71 & 86.70 & 4.07 & 77.10 & 3.81 & $<0.001$ \\
\hline After 15 mins. & 85.80 & 5.69 & 73.30 & 4.99 & 86.80 & 3.69 & 74.60 & 4.21 & $<0.001$ \\
\hline After 20 mins. & 84.30 & 4.74 & 70.80 & 4.02 & 85.50 & 3.17 & 72.70 & 4.41 & $<0.001$ \\
\hline After 30 mins. & 83.90 & 5.37 & 74.90 & 4.61 & 85.80 & 5.02 & 75.60 & 3.87 & $<0.001$ \\
\hline After 40 mins. & 87.20 & 4.23 & 69.10 & 3.01 & 87.70 & 2.62 & 70.80 & 2.71 & $<0.001$ \\
\hline After 50 mins. & 82.50 & 3.36 & 74.70 & 4.78 & 82.60 & 2.98 & 72.95 & 4.49 & $<0.001$ \\
\hline After 60 mins. & 87.40 & 4.36 & 73.90 & 3.86 & 89.30 & 2.36 & 73.68 & 3.15 & $<0.001$ \\
\hline
\end{tabular}

\section{CONCLUSION}

Administration of low-dose Fentanyl-Midazolam combination prior to Sevoflurane and Propofol induction decreases patient's anxiety levels and time of loss of eyelash reflex.

Low-dose Fentanyl-Midazolam combination prior to induction allows more rapid and less eventful LMA insertion in fewer attempts. Premedication also maintains blood pressure and heart rate at lower levels. Low-dose Fentanyl-Midazolam combination provides more safe and satisfactory condition for LMA insertion.

\section{REFERENCES}

1. Brian AI. The Laryngeal mask-a new concept in airway management. Br J Anaesth 1983;55(8):801-5.

2. Nishiyama T, Matsukawa T, Yokoyama $T$, et al. Rapid inhalation induction with $7 \%$ sevoflurane combined with intravenous midazolam. J Clin Anaesth 2002;14(4):290-5.

3. Ti LK, Chow MY, Lee TL. Comparison of sevoflurane with propofol for laryngeal mask airway insertion in adults. Anaesth Analg 1999;88(4):908-12.

4. Sayyid SMS, Aouad MT, Taha SK, et al. A comparison of sevoflurane-propofol versus sevoflurane or propofol for laryngeal mask airway insertion in adults. Anaesth Analg 2005;100(4):1204-9.

5. Lesage S, Drolet P, Donati F, et al. Low dose midazolam fentanyl combination improves sevoflurane induction in adults. Can J Anaesth 2009;56(10):733-9.

6. Ganatra SB, Mello JD, Butani M. Conditions for insertion of laryngeal mask airway: comparison between sevoflurane and propofol using fentanyl as a co-induction agent. Eur J Anaesth 2002;19(5):371-5.
7. Cork RC, Depa RM, Standen JR. Prospective comparison of use of the laryngeal mask and endotracheal tube for ambulatory surgery. Anaesth \& Analg 1994;79(4):719-27.

8. Zimmert $\mathrm{M}$, Zwirner $\mathrm{P}$, Kruse $\mathrm{E}$, et al. Effect on vocal function and incidence of laryngeal disorder when using laryngeal mask airway in comparison with an endotracheal tube. Eur J Anaesth 1999;16(8):511-5.

9. Tahir MS, Kha NA, Masood M, et al. A comparison of pressor responses following laryngeal mask airway vs laryngoscopy and endotracheal tube insertion. Anaesth Pain \& Intensive Care 2008;12(1):531-46.

10. Hall JE, Stewart JI, Harmer M. Single breath inhalation induction of sevoflurane anaesthesia with and without nitrous oxide: a feasibility study in adults and comparison with an intravenous bolus of propofol. Anaesthesia 1997;52(5):410-5.

11. Muzi M, Colinco MD, Robinson BJ, et al. The effects of premedication on inhaled induction of anaesthesia with sevoflurane. Anaesth Analg 1997;85(5):1143-8.

12. Shlomo B, Abd-El-Khalim H, Ezry J, et al. Midazolam acts synergistically with fentanyl for induction of anaesthesia. Br J Anaesth 1990;64(1):45-7.

13. Katoh T, Nakajima G, Moriwaki G, et al. Sevoflurane requirements for tracheal intubation with and without fentanyl. Br J Anaesth 1999;82(4):561-5.

14. Sivalingam P, Kandasamy R, Madhavan G, et al. Conditions for laryngeal mask insertion-a comparison of propofol versus sevoflurane with or without alfentanil. Anaesthesia 1999;54(3):271-6.

15. Cardinal V, Martin R, Tétrault JP, et al. Bradycardia \& asystole during induction with sevoflurane and sufentanil. Can J Anaesth 2004;51(8):806-9. 